\title{
Isolated Blunt Submandibular Gland Injury after a Fall from a Bicycle
}

\author{
Bisikletten Düşme Sonrası İzole Künt Submandibular Gland Yaralanması
}

\author{
Salih Ekinci', Can Aktaş' ${ }^{1}$, Yoldaş Demirtaş ${ }^{1}$, Abdülkerim Erten² \\ 'Department of Emergency, Koç University Training and Research Hospital, İstanbul, Turkey \\ 2Department of Emergency, Silopi State Hospital, Şırnak, Turkey
}

\section{ABSTRACT}

Introduction: Injury to deep neck structures should be considered during emergency room (ER) admissions in patients with a chief complaint of swelling in the neck, particularly when there is a history of trauma to the neck. Life-threatening conditions should be assessed, diagnosis should be made using appropriate imaging modalities, and treatment should be planned accordingly.

Case Report: A 30-year-old male presented to the ER with the chief complaint of a swollen neck $2 \mathrm{~h}$ after he fell off a bicycle. Based on the ultrasound and computed tomography analysis, he was diagnosed with isolated submandibular injury.

Conclusion: Isolated submandibular injury following a blunt trauma is a rare condition. Obtaining appropriate imaging modalities is helpful in confirming the diagnosis. Patients with blunt trauma should also be carefully assessed for other, nonapparent injuries.

Keywords: Submandibular gland, trauma, blunt injury, submandibular hemorrhage

Received: 20.03.2015 Accepted: 30.04.2015

Available Online Date: 27.05.2015

\section{ÖZET}

Giriş: Acil servise boyunda şişlik ile başvuran hastalarda, özellikle travma anamnezi varsa, boyun bölgesi yapılarının yaralanması düşünülmelidir. Hayatı tehdit edebilecek durumlar hızla gözden geçirilmeli ve uygun görüntüleme yöntemleri ile tanıya ulaşılarak tedavi planlanmalıdır.

Olgu Sunumu: Acil servise başvurmadan 2 saat önce bisikletten düşme sonucu boynunda şişlik gelişen, ultrasonografi ve bilgisayarlı tomografi görüntülemeleri sonucunda da izole submandibular bez yaralanması tanısı konan bir hasta sunulmuştur.

Sonuç: Künt travma sonucu gelişen izole submandibular bez yaralanması oldukça nadirdir. Tanıda radyolojik görüntüleme yöntemleri yardımcı olur. Hastalar ek yaralanmalar açısından dikkatle değerlendirilmelidir.

Anahtar Kelimeler: Submandibular bez, travma, künt yaralanma, submandibular hemoraji

Geliş Tarihi: 20.03.2015 Kabul Tarihi: 30.04.2015

Çevrimiçi Yayın Tarihi: 27.05.2015

\section{Giriş}

Parotis, submandibular ve sublingual bezler majör tükürük bezleridir. Bu bezlerin izole yaralanmaları oldukça seyrektir. Submandibular ve sublingual bezyaralanmaları anatomik pozisyonları nedeniyle parotis bezi ve tükürük kanal yaralanmalarından daha nadir görülür. Etiyolojiden çoğunlukla penetran travmalar sorumludur (1). Bu yazıda, bisikletten düşme sonucu izole künt submandibular bez yaralanması meydana gelen bir olgu sunulmuştur.

\section{Olgu Sunumu}

Otuz yaşında erkek hasta, acil servise gelmeden yaklaşık 2 saat önce bisikletten düşme ve sonrasında sağ boyun bölgesinde şişlik oluşması şikayetleriyle başvurdu. Düştüğünde çene ve boyun bölgesini, sivri olmayan sert bir zemine çarptığını belirtti. Boynundaki şişliği, çarptıktan yaklaşık 1 saat sonra fark ettiğini ve bu bölgede boyun hareketleriyle hafif derecede ağrı olduğunu ifade etti. Yutkunma güçlüğü veya nefes darlığı gibi solunum yolunu tehdit eden bir semptom bulunmamaktaydı. Hastanın 
tıbbi hikayesinde herhangi bir kronik hastalığı veya düzenli bir ilaç kullanımı yoktu.

Fizik muayenesinde bilinç açık ve koopere, vital parametreleri normal sınırlarda idi. İnspeksiyonda sağ boyun - submandibular üçgende $4 \times 2 \mathrm{~cm}$ boyutlarında şişlik vardı, eritem veya ekimoz yoktu (Şekil 1). Ağız içi ve orofarenks incelemesinde eritem, şişlik veya hemorajiye rastlanmadı.

Boyundaki şişlik, travmaya bağlı vasküler yapıların anevrizma/ diseksiyonu olabileceği şüphesiyle oskülte edildi; üfürüm saptanmadı. Palpasyonda hassasiyet ve hafif ISı artışı vardı. Tril veya pulsasyon alınmadı. Cilt altı krepitasyon yoktu. Mandibula palpasyonunda hassasiyet veya krakman yoktu. Diğer sistemlerin muayenesinde patoloji saptanmadı.

Kas veya beziçiyaralanma ön tanısıylayapılan boyun ultrasonografisinde, sağ submandibular bezin boyutlarında artış ve parankiminde heterojenite saptandı. Bez içinde yaklaşık $3.5 \times 1.5 \mathrm{~cm}$ boyutlarında sınırları belirsiz hipoekoik görünüme rastlandı (Şekil 2). Bu görüntü submandibular bez içi kanama ile uyumluydu. Sol submandibular bez ultrasonografisi ise normaldi.

Vasküler yapıların değerlendirilmesi amacıyla hastaya, intravenöz kontrastlı boyun bilgisayarlı tomografi (BT) görüntülemesi yapıldı. Sağ submandibular bez boyutunda artma ve bez içinde hemorajiyle uyumlu hipodens alan saptandı. Bez içerisinde veya kanalda taş gözlenmedi ve kanal dilatasyonu saptanmadı. Vasküler yapılarda patolojiye rastlanmadı. İnceleme kesitlerindeki kemik yapılarda fraktür saptanmadı (Şekil 3).

Bu mevcut bulgularla kulak burun boğaz kliniğine konsülte edilen hasta, tedavi ve komplikasyonlar açısından takip amaçlı servise yatırıldı. Profilaktik olarak seftriakson 1 gram intravenöz 2x1 başlandı. Ağrı yönetimi amaçlı metamizol sodyum tedavisi uygulandı. Şişliğin gerilemesi ve komplikasyon gelişmemesi üzerine 2 gün sonra, ani ve aşırı boyun hareketlerinden kaçınması önerilerek taburcu edildi. Ayaktan takibinin 10. günündeki kontrol başvurusunda şişliğin tamamen geçtiği ve ağrı veya başka bir şikayetinin olmadığı gözlendi.

Bilgilendirilmiş yazılı hasta onamı, bu olgu sunumuna katılan hastadan alınmıştır.

\section{Tartışma}

Mandibulanın koruyucu anatomik yerleşimi nedeniyle submandibular bezin izole, künt travmatik yaralanmaları oldukça nadirdir (2). Burada sunulan hastamızda da, komşu yapılarda veya diğer sistemlerde yaralanma olmadan, künt travma sonucu izole submandibular bez yaralanması meydana geldi.

Akut boyun şişliğine neden olan ciddi durumlar arasında karotid arter diseksiyonu, trakea rüptürü ve farenks yaralanması sayılabilir $(3,4,5)$. Bu tanılar açısından hızla değerlendirme ve müdahale hayat kurtarıcı olacaktır. Ayrıca, boyunda şişlik ile başvuran hastalarda sialolitiazis de akla gelmesi gereken bir tanıdır. Sialolitiazisin radyolojik bulguları,

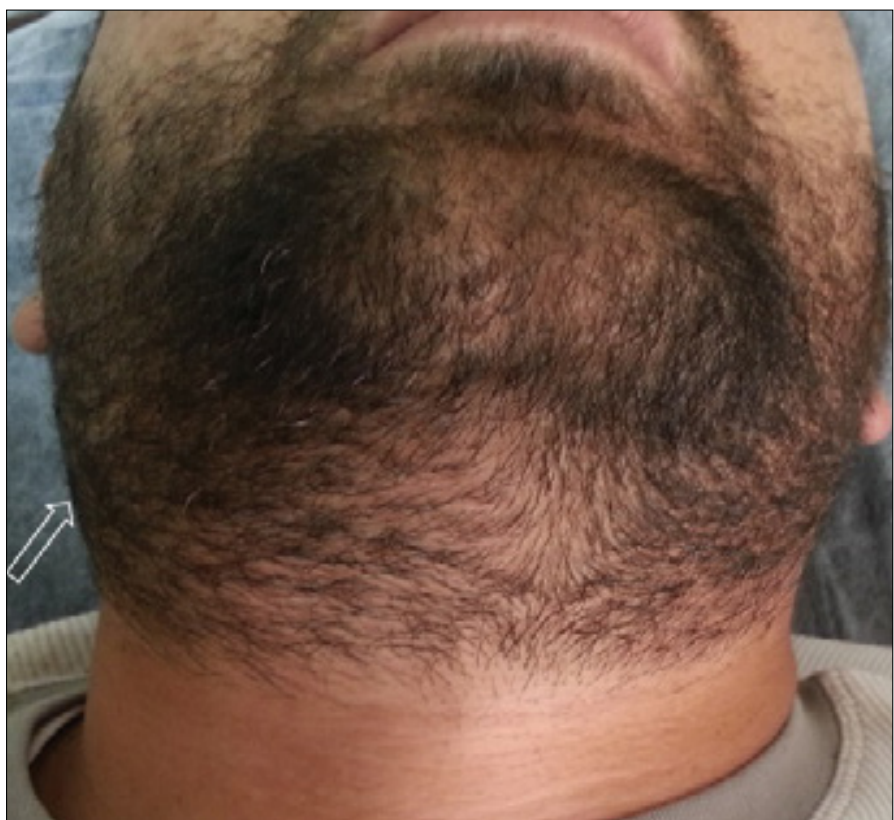

Şekil 1. Sağ submandibular üçgende şişlik (beyaz ok)

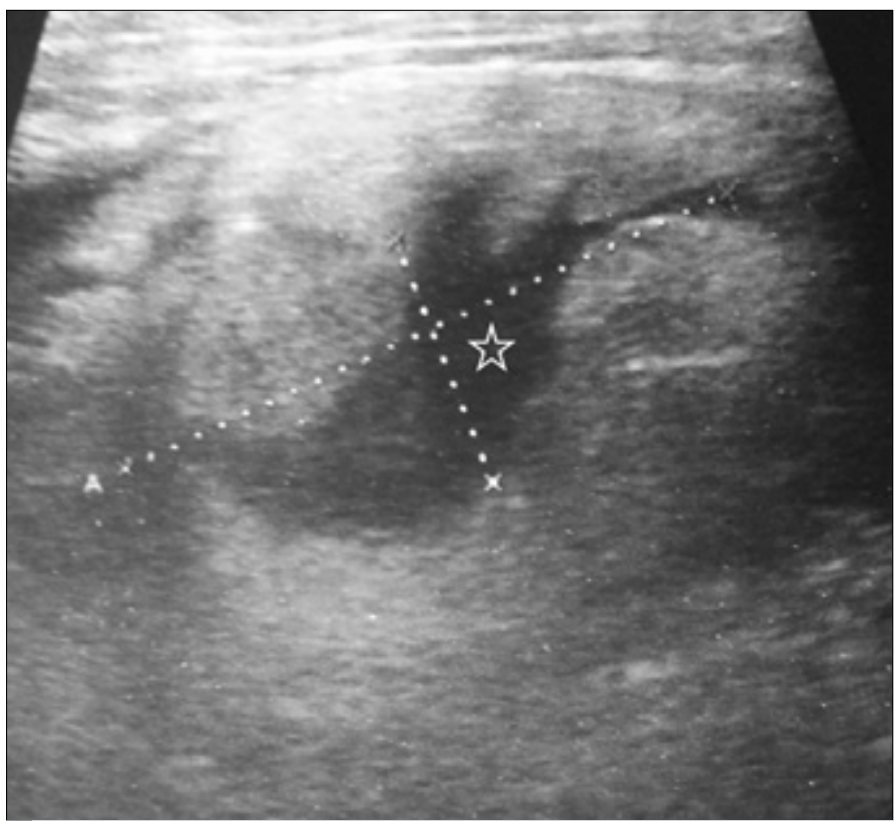

Şekil 2. Sağ submandibular bez ultrasonografisi; boyutları artmış ve bez içinde hipoekoik görünümlü sıvı (beyaz yıldız)

submandibular hemoraji ile benzerlik gösterir. Bununla beraber, submandibular bezdeki şişmenin travma sonucu meydana gelmesi, hızla oluşması, görüntülemede bez içindeki hemorajinin yaygın olmaması, tanıyı hemorajiye yaklaştıran ipuçlarıdır. Hastamızda, tüm BT kesitlerini incelediğimizde, taş veya kanal genişlemesi saptamadık ve hemorajiyle uyumlu hipodens alanın, mandibulanın hemen altına gelen lokal bir bölgede yoğun olduğunu belirledik.

Tükürük bezi yaralanmaları genellikle çoklu travma hastalarında meydana gelir ve bu nedenle gözden kaçabilir. Ancak inspeksiyonda görülecek derecede büyüklüğe ulaştığında tükürük bezi 


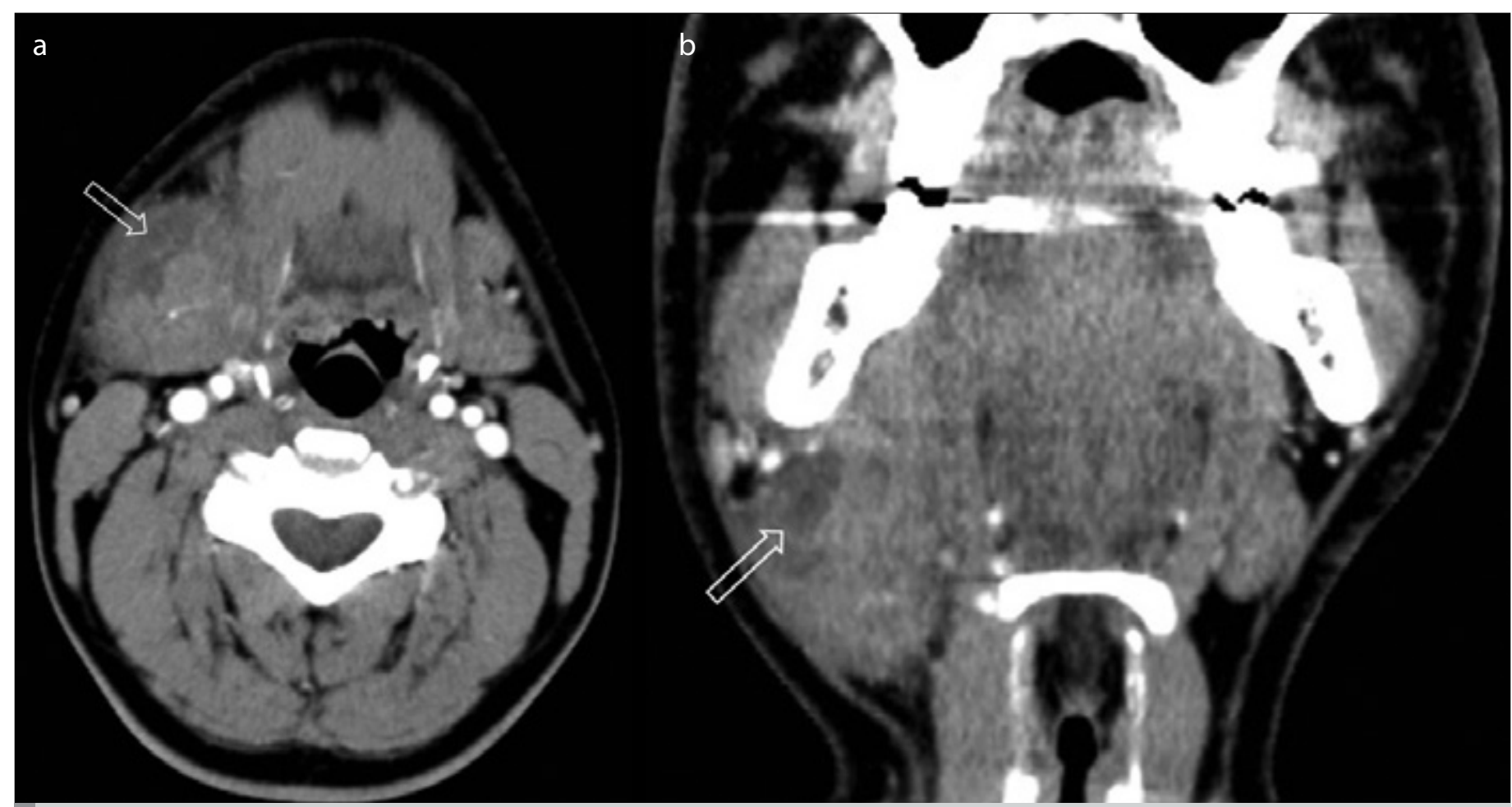

Şekil 3. a, b. Boyun kontrastlı bilgisayarlı tomografisi, aksiyal kesit (a), koronal kesit; bez boyutunda artma ve bez içinde hipodens alan (beyaz oklar) (b)

yaralanmasını belirlemek daha kolaydır. Akut yaralanmaların primer nedeni ateşli silahlar veya bıçak yaralanmaları gibi penetran travmalardır. Künt travmalardan motorlu araç kazaları, spor ilişkili yaralanmalar, yumruk veya tekme gelmesi gibi şiddet eylemleri ve aşırı manipülasyonlar sorumludur. Ayrıca savaş veya mesleki yaralanmalar sonucunda patlama yaralanmaları da görülebilir $(6,7)$. Yaralanmalara genellikle mandibula veya zigomatik kemik fraktürleri eşlik eder (8).

Akut dönemde tanı konamayan veya etkin olarak yönetilemeyen hastalar, travmadan aylar sonra kronik sekelle başvurabilirler (6). Bu nedenle, ek yaralanmaların saptanması ve morbiditenin önlenmesi amacıyla cilt, kemik yapılar, dişler, damarlar ve tükürük kanalları dikkatli değerlendirilmelidir. Ayrıca tükürük bezlerinin yakınında seyreden önemli kranial sinirler (trigeminal, fasial ve hipoglossal) yaralanma açısından tetkik edilmelidir (8). Görüntüleme yöntemleri olarak ultrasonografi, BT, BT anjiografi veya manyetik rezonans inceleme (MRi) kullanılabilir. BT anjiografi, vasküler yapıların da değerlendirilmesi avantajını sağlar. MRi, yüksek yumuşak doku kontrastı sağlaması nedeniyle, eşlik eden spinal veya serebral yaralanmalarda ya da tükürük bezlerinin daha ayrıntılı incelenmesi amacıyla kullanılabilir. Duktal sistem yaralanması şüphesinde hastalar sialografi ile incelenebilir $(8,9)$. Biz de hastamızda ileri görüntüleme yöntemi olarak BT anjiografi görüntülemesi yaptık ve vasküler ve komşu yapılarda ek patoloji saptamadık.

İzole künt submandibular bez yaralanması olan hastalarda konservatif yaklaşım genellikle yeterlidir. Künt travmalar parankimal kontüzyon, hematom veya laserasyon ve bazen de fibrozis, sialadenit, sialosel veya mukosel formasyonuna neden olurken, penetran yaralanmalar duktal lezyonlar ve sıklıkla fistül oluşumuna yol açar (2). Duktal laserasyon saptandığında, bu gibi komplikasyonların gelişme riski yüksek olduğundan, acil cerrahi onarım düşünülmelidir $(7,8)$. Hastamızda izole künt yaralanma olması ve komplikasyon gelişmemesi nedeniyle konservatif yaklaşımı tercih ettik.

Antibiyotikler, riskli hastalarda sekonder enfeksiyonların önlenmesi ya da eş zamanlı enfeksiyonların tedavisi açısından önerilir. Bu amaçla ikinci ve üçüncü kuşak sefalosporinler, penisilinler veya klindamisin seçilebilir. Antikolinerjiklerin, tükürük üretim ve akımını yavaşlatması ve bez irritasyonunu azaltması nedeniyle prognozu iyileştirdiğini gösteren çalışmalar mevcuttur $(7,10)$. Üriner retansiyon, fotofobi ve taşikardi gibi yan etkileri ise kullanımlarını kısıtlar. Biz de hastamıza, profilaktik amaçlı seftriakson 1 gram 2x1 tedavisi başladık.

\section{Sonuç}

Tükürük bezleri yaralanmaları nadir görülmelerine karşın, hastalarda anlamlı morbiditeye yol açabilirler. Bu nedenle travma ile başvuran hastalarda, ayrıntılı fizik muayenede tükürük bezi yaralanmaları akılda tutulmalıdır. Hastalar, ultrasonografi gibi hızlı tanı imkanı sağlayan görüntüleme yöntemleri ile değerlendirilmelidir. Ayrıca ek yaralanmalar ve komplikasyonlar açısından gerekli durumlarda ileri tetkikler kullanılmalıdır. Hastanın mevcut durumuna göre konservatif ya da cerrahi tedavi seçilebilir.

Informed Consent: Written informed consent was obtained from patient who participated in this case.

Peer-review: Externally peer-reviewed. 
Author Contributions: Concept - S.E.; Design - S.E., A.E.; Supervision - C.A.; Materials - S.E.; Data Collection and/or Processing - S.E., Y.D.; Analysis and/or Interpretation - S.E., C.A.; Literature Review - Y.D., A.E.; Writer - S.E., C.A.; Critical Review - C.A.

Conflict of Interest: The authors declared no conflict of interest.

Financial Disclosure: The authors declared that this study has received no financial support.

Hasta Onamı: Yazılı hasta onamı bu olguya katılan hastadan alınmıştır.

Hakem değerlendirmesi: Dış bağımsız.

Yazar Katkıları: Fikir - S.E.; Tasarım - S.E., A.E.; Denetleme - C.A.; Malzemeler S.E.; Veri toplanması ve/veya işlemesi - S.E., Y.D.; Analiz ve/veya yorum - S.E., C.A.; Literatür taraması - Y.D., A.E.; Yazıyı yazan - S.E., C.A.; Eleştirel İnceleme - C.A.

Çıkar Çatışması: Yazarlar çıkar çatışması bildirmemişlerdir.

Finansal Destek: Yazarlar bu çalışma için finansal destek almadıklarını beyan etmişlerdir.

\section{Kaynaklar}

1. Lazaridou M, lliopoulos C, Antoniades K, Tilaveridis I, Dimitrakopoulos I, Lazaridis N. Salivary Gland Trauma: A Review of Diagnosis and Treatment. Craniomaxillofac Trauma Reconstr 2012; 5: 189-96. [CrossRef]
2. Singh B, Shaha A. Traumatic submandibular salivary gland fistula. J Oral Maxillofac Surg 1995; 53: 338-9. [CrossRef]

3. Khan MA, Moffat A, Ahmed W, Wong J, Jadun C. Common carotid artery dissection: A rare cause of acute neck swelling. Ear Nose Throat J 2015; 94: 111-2.

4. Hager J, Gunkel AR, Riccabona U. Isolated longitudinal rupture of the posterior tracheal wall following blunt neck trauma. Eur J Pediatr Surg 1999; 9: 104-8. [CrossRef]

5. Scioscia KA, April MM. Pediatric otolaryngology: isolated cervical subcutaneous emphysema. Am J Otolaryngol 1994; 15: 155-7. [CrossRef]

6. Guntinas-Lichius O. Trauma to the Salivary Glands and their Management. In: Anniko M, Bernal-Sprekelsen M, Bonkowsky V, Bradley P, lurato S, Editors. Otorhinolaryngology, Head and Neck Surgery (European Manual of Medicine). Heidelberg, Berlin: Springer-Verlag, 2010: 349-52. [CrossRef]

7. Tonerini M, Fratini L, Grassi L, Ravenna V, Tozzini A, Trincavelli F, et al. Blunt submandibular gland trauma: acute $C T$ findings. Emerg Radiol 2002; 9: 116-8. [CrossRef]

8. Smith JE, Ruggiero FP. Mandibular Fractures. In: Bailey BJ, Johnson JT, Newlands SD, Editors. Head and Neck Surgery: Otolaryngology. 4th ed. New York, NY: Lipincott Williams \& Wilkins, 2006: 961-74.

9. Bowen BC. MR angiography versus $C T$ angiography in the evaluation of neurovascular disease. Radiology 2007; 245: 357-61. [CrossRef]

10. Parekh D, Glezerson G, Stewart M, Esser J, Lawson HH. Post-traumatic parotid fistulae and sialoceles. A prospective study of conservative management in 51 cases. Ann Surg 1989; 209: 105-11. [CrossRef] 